\title{
Effects of Inspiratory Muscle Exercise Using Biofeedback on Inspiratory Muscle Activity and Pulmonary Function in Patients with Stroke
}

\author{
Dae-Jung Yang, Seung-Kyu Park, Jeong-II Kang, Je-Ho Kim, Sung-Yong Kim \\ Department of Physical Therapy, Graduate School, Sehan University, Yeongam-gun, Jeollanam-do, Korea
}

\begin{abstract}
Purpose: This study was conducted to determine the influence of inspiratory muscle exercise using visual biofeedback and inspiratory muscle exercise with diaphragm breathing retraining in stroke patients in regard to inspiratory muscle activity and respiratory function and to provide fundamental information on intervention for improvement of pulmonary function in stroke patients.

Methods: The current study measured and analyzed inspiratory muscle activity and pulmonary function of 15 randomly selected subjects in a Biofeedback inspiratory muscle exercise (BIE) group that uses visual feedback and 15 subjects in the Diaphragm breathing exercise (DBE) group that uses breathing retraining before and after intervention. Intervention was performed for 30 minutes, 5 times a week, for 8 weeks. Subjects were measured for muscle activity of upper trapezius muscle and lattisimus dorsi muscle using a surface electromyography system and maximum inspiratory pressure was measured using a respiratory measurement device. For homogeneity test of subjects, independent t-test was performed and ANCOVA was performed for comparison of inspiratory muscle activity and pulmonary function between groups.
\end{abstract}

Results: In the study results, the BIE group showed more significant muscle activity than the DBE group in upper trapezius muscle and lattisimus dorsi muscle $(p<0.001)$. In addition, the BIE group showed more pressure than the DBE group in maximum inspiratory pressure $(p<0.001)$.

Conclusion: Based on the current study, performing biofeedback respiration exercise simultaneously with breathing retraining in stroke patients can provide more efficient respiratory physical therapy. In addition, it is considered that consistent study on the effectiveness is necessary to further improve clinical availability.

Keywords: Stroke, Inspiratory muscle exercise, Muscle activity, Pulmonary function

\section{서 론}

뇌졸중 환자는 운동기능과 감각기능의 장애로 신체적 활동에 심각 한 제약을 받게 되고,' 운동피질과 피라미드로의 손상은 자세 운동 조절 능력에 손상을 보이고 몸통 분절의 분리되지 않은 움직임은 몸 통근육의 동시수축이 나타나게 된다. 몸통 근육의 동시수축과 분리 되지 않은 움직임은 손상측 가슴벽(thoracic wall)의 움직임에 감소와 근육의 특성에 변화를 야기시키며 유산소 운동능력과 호흡능력의 감소를 보이고 신체활동에 제한을 가져온다. ${ }^{3}$ 호흡은 공기와 혈액 사 이의 환기-관류 교환역할을 하며 호흡근과 그들의 신경학적 조절에 의해 이루어진다. ${ }^{4}$ 호흡의 주기는 들숨과 날숨으로 구분되어 있으며

Received Sep 15, 2015 Revised Oct 15, 2015

Accepted Oct 19, 2015

Corresponding author Sung-Yong Kim

E-mail gsy527@naver.com
들숨 시에는 주로 가로막이 작용근으로 사용되며 날숨 시에는 배속 빗근, 배바깥빗근, 배곧은근 등이 작용근으로 사용된다. ${ }^{5}$ 평상시 안 정된 호흡은 가슴벽과 폐의 탄력성에 의해 능동적으로 날숨이 일어 나야 하고, 동시에 들숨을 하는 동안 갈비사이근과 목갈비근, 가로막 의 주기적인 활동이 일어나야 한다. ${ }^{\circ}$ 약화된 호흡 근육은 뇌졸중 환 자들의 일상생활 능력을 감소시키고, 특히 누운 자세에서 앉기, 앉은 자세에서 서기, 걷기 등과 같이 많은 노력을 요구하는 활동에서 피로 와 호흡장애를 보인다. 신경학적 손상이나 폐의 약화로 감소된 들숨 근육의 근력을 가지고 있다면, 들숨 근육의 근력 강화 훈련이 재활에 선택되어야 하고, 삼킴과 기침 배출과 같은 기능에 어려움을 호소한 다면 호기 근육의 근력 강화 훈련이 재활에 집중되어야 한다. Lanini
Copylight (C)2015 The Korea Society of Physical Therapy

This is an Open Access article distribute under the terms of the Creative Commons Attribution Non-commercial License (Http:// creativecommons.org/license/by-nc/3.o.) which permits unrestricted non-commercial use, distribution, and reproduction in any medium, provided the original work is properly cited. 
등은 뇌졸중 환자에게서 수의적인 과환기 동안 마비측 흥부의 호흡 운동과 횡격막 운동 및 근활성도가 감소된다고 하였다. 호흡근의 기 능은 환자의 운동능력 향상과 운동에 대한 심장호흡계가 정상적으 로 반응하는 것에 기여하는데, 이러한 호흡근 기능을 개선시키기 위 해서는 근력의 증가가 수반되어야 한다. ${ }^{9}$ 호흡훈련은 호흡근이 약화 된 환자에게 호흡근의 기능을 향상시킬 뿐만 아니라, ${ }^{10}$ 운동능력을 증가시키고 호흡곤란을 개선시켜 삶의 질을 향상시킬 수 있다. 그러 나 뇌졸중 질환과 같은 신경학적 손상을 받은 환자들은 주로 좌식생 활을 하기 때문에 힘든 활동이나 흉부 감염으로 인해 갑작스럽게 산 소요구량이 증가하는 상황이 발생되기 전까지는 호흡문제가 간과되 기 쉽다.9

$\mathrm{Kim}$ 등"은 뇌졸중 환자에게 흥곽확장 저항운동을 중재하여 흥곽 확장범위와 최대들숨압력에 유의한 증가를 나타냈고, Britto 등'2은 뇌졸중환자에게 호흡 저항기기를 이용한 호흡운동을 중재하여 최 대들숨압력과 들숨근 지구력에 유의한 증가를 나타냈다. 하지만 일 반적인 호흡 훈련은 호흡량에 대한 생체되먹임의 제공이 부족하고 대상자들의 최대 노력을 이끌어내기 어렵기 때문에 최근 생체되먹임 을 이용한 호흡훈련이 대두되고 있다. Seo 등 ${ }^{13}$ 은 뇌졸중 환자에게 되 먹임 호흡훈련을 중재하여 보장시간, 동시지지기, 입각기, 보행속도, 기능적 보행 성취도 측정에서 유의한 증가를 나타냈고, Lee 등 ${ }^{14}$ 은 중 년 남성에게 되먹임 호흡운동을 중재하여 흥곽용적과 폐기능에 유 의한 증가를 나타냈다. 생체되먹임은 근육 또는 움직임에 대한 실시 간으로 정보를 제공함으로써 정상적인 움직임과 신체정렬 상태 유지 및 적절한 근수축을 이끌어내는 데 효과적이며, 운동학습을 촉진시 키는 데 효과적인 방법이라고 하였다. ${ }^{15}$

선행연구에서 보고된 바와 같이 심폐기능의 약화는 뇌졸중 환자 의 생명유지와 기능향상에 중요한 요소이다. 이에 따른 호흡기능 증 진을 위한 다양한 호흡훈련을 시행한 연구는 있었으나 수치화된 데 이터를 실시간으로 제공하는 시각적 생체되먹임을 제공하는 들숨근 훈련에 대한 연구는 부족한 실정이다. 따라서 본 연구의 목적은 뇌졸 중 환자에게 시각적 생체되먹임을 이용한 들숨근 훈련과 가로막 호 흡법 재교육을 통한 들숨근 훈련이 들숨근 활성도와 폐기능에 미치 는 영향에 대해 알아보고 뇌졸중 환자의 폐기능 향상을 위한 중재 방 법에 기초정보를 제공하고자 한다.

\section{연구방법}

\section{1. 연구대상}

본 연구는 전남 소재의 M 병원에서 뇌졸중으로 인해 반마비 진단을 받고 기능회복을 위해 치료를 받고 있는 입원환자들 중 실험방법에 대하여 충분한 설명을 듣고 자발적으로 참여하기로 동의한 30 명을
Table 1. General characteristic of subjects

\begin{tabular}{lcccc}
\hline & $\begin{array}{c}\text { BIE group } \\
(n=15) \\
\text { Mean } \pm \text { SD }\end{array}$ & $\begin{array}{c}\text { DBE group } \\
(n=15) \\
\text { Mean } \pm \text { SD }\end{array}$ & $t$ & $p$ \\
\hline Age (year) & $67.9 \pm 6.8$ & $68.9 \pm 6.3$ & -0.37 & $0.98^{*}$ \\
Height (cm) & $162.8 \pm 7.1$ & $160.6 \pm 6.9$ & 0.80 & $0.75^{*}$ \\
Weight (kg) & $64.2 \pm 10.3$ & $60.2 \pm 8.6$ & 1.10 & $0.38^{*}$ \\
Stroke duration (month) & $5.6 \pm 2.5$ & $6.3 \pm 2.6$ & -0.68 & $0.94^{*}$ \\
UT \%RVC (\%) & $104.2 \pm 1.8$ & $103.7 \pm 2.2$ & 0.67 & $0.41^{*}$ \\
LD \%RVC $(\%)$ & $104.5 \pm 2.2$ & $104.2 \pm 2.4$ & 0.35 & $0.41^{*}$ \\
MIP $\left(\mathrm{cmH}_{2} \mathrm{O}\right)$ & $34.9 \pm 3.4$ & $35.0 \pm 2.8$ & -0.14 & $0.66^{*}$ \\
\hline
\end{tabular}

\%RVC: \% reference voluntary contraction, UT: Upper trapezius muscle, LD: Latissimus dorsi muscle, MIP: Maximal inspiratory pressure, Mean \pm SD: mean \pm standard deviation, BIE group: Biofeedback inspiratory muscle exercise group, DBE group: Diaphragm breathing exercise group. ${ }^{*} \mathrm{p}>0.05$.

선정하였다. 세부적인 선정기준은 뇌졸중 진단을 받고 1년을 초과하 지 않은 자, 뇌졸중 발병 이전에 특별한 폐 질환의 병력이 없는 자, 선 천적 가슴우리의 변형이나갈비뼈 골절 등의 동반 손상이 없는 자, 폐 기능의 향상을 위해 특별한 치료를 받지 않았던 자, 기능적 보행지수 (functional ambulation category)가 3-5인 자, 한국형 간이 정신상태 검 사(MMSE-K) 점수가 24점 이상으로 의사소통이 가능한 자로 선정하 였다(Table 1).

\section{2. 실험방법}

본 연구는 시각적 되먹임을 이용한 생체되먹임 들숨근 훈련 그룹 (Biofeedback inspiratory muscle exercise group, BIE group) 15명, 호흡법 재교육을 이용한 가로막 호흡법 훈련 그룹(Diaphragm breathing exercise group, DBE group) 15 명으로 각각 무작위 임의 선정하여 중재 전 후 들숨근 활성도와 폐기능을 측정하여 분석하였다.

\section{1) 생체되먹임 들숨근 훈련}

본 연구에서는 들숨근 훈련을 위해 시각적 되먹임을 할 수 있도록 고 안된 Powerbreathe K5 (Powerbreathe, UK)를 이용하였다. Powerbreathe $\mathrm{K} 5$ 는 본체와 마우스피스, 코마개로 구성되어 있고 스크린과 연결하 여 들숨근 훈련을 하는 동안 시각적 되먹임을 제공한다. 훈련은 Klusiewicz 등 16 의 연구를 기반으로 훈련 프로토콜을 적용하였다. 훈련시 간은 총 30 분으로 3 session으로 구성되며 1 session당 5 분의 훈련과 5 분의 휴식 시간을 제공하고, 5 분의 훈련 시간 중 앞, 뒤 1 분씩 2 분은 warm up과 cool down 단계로 훈련강도의 $50 \%$ 의 힘을 가한다. 본 운동 의 운동강도는 Pradon 등기이 이용한 주관적 운동자각도(rating of perceived exertion, PRE)인 Borg's scale (6-20까지 15단계로 구성)을 사 용하여 11 (가볍다)- 13 (약간 힘들다)로 하였으며, 8 주 동안 주 5 회, 1 일 30 분의 훈련을 제공받았다. 


\section{2) 호흡법 재교육 훈련}

호흡법 재교육 훈련은 Jones 등 ${ }^{18}$ 의 연구를 바탕으로 가로막 호흡법 운동을 이용하였다. 누운 자세에서 어깨와 가슴 근육을 이완시킨 후 한 손을 앞가슴 복장뼈 중간부에, 다른 손은 배 위에 얹고 들숨 시 배 위에 얹은 손이 앞으로 나오게 하고 날숨 시 내려감을 느끼도록 하여 가로막저항운동을 하였다. 훈련시간은 총 30 분으로 3 session으로 구 성되며 1 session당 5 분의 훈련과 5 분의 휴식 시간을 제공하고, 8 주 동 안 주 5 회, 1 일 30 분의 훈련을 제공하였다.

\section{3. 측정방법}

1) 표면근전도 시스템

근활성도를 측정하기 위해 MP100 표면근전도 시스템(Biopac System Inc., USA)을 이용하였고, 디지털신호로 변환된 자료는 개인용 컴퓨터 에서 Acqknowledge 3.91 소프트웨어를 이용하여 자료 처리하였다. 표 면근전도 신호에 대한 피부저항을 최소화하기 위해 부착부위의 털 을 제거하고 가는 사포로 3-4회 문질러 피부 각질층을 제거한 후, 소 독용 알코올 솜으로 피부를 깨끗이 하였다. 부착근육은 위등세모근 과 넓은등근에 부착하였고 이극전극은 각 근육의 근힘살(muscle belly)에 근섬유의 방향과 평행하게 부착하였다. 표본추출률(sampling rate)은 $1,024 \mathrm{~Hz}$ 로 설정하였고, 잡음을 최소화하기 위해 대역 여과 필 터(notch filter)는 $60 \mathrm{~Hz}$, 대역 통과 필터(band pass filter) 20-450 Hz로 설정하였으며 수집된 신호는 RMS 처리하였다(Figure 1). ${ }^{19}$

\section{2) 근활성도의 표준화}

본 연구에서 근활성도를 표준화하기 위해 특정 동작의 근수축을 기 준수축(reference voluntary contraction, RVC)으로 하여 이를 표준화하 는 \%기준수축(\%RVC)방법을 이용하였다. 의자에 편안하게 앉은 자세 를 취하게 한 후 자연스러운 호흡을 하는 5 초 동안 측정 근육들의 근 활성도를 측정한 뒤 처음과 마지막 1 초씩을 제외한 3 초의 신호를 분 석하여 RVC값을 산출하였고, "공기를 입 속으로 크게 들이 마신 후

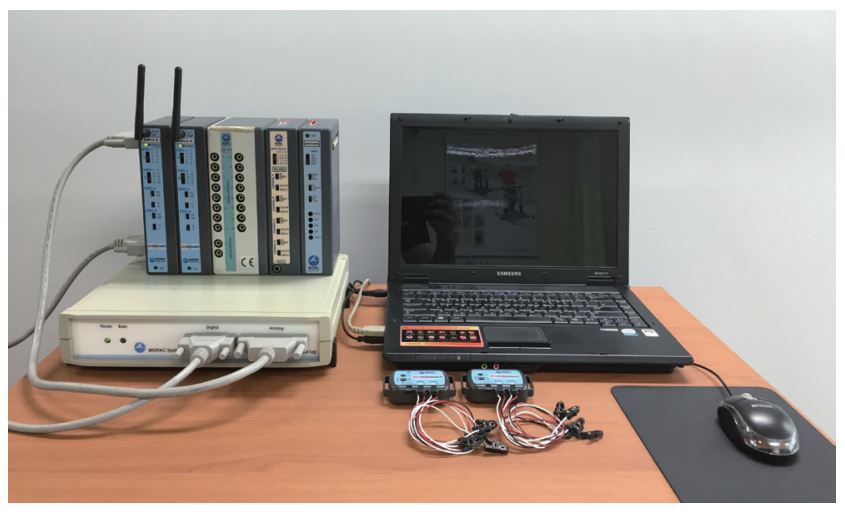

Figure 1. sEMG.
입을 다물고 5 초간 유지하세요."라고 구호를 주어, 이때 발생되는 동 일한 근육의 근활성도 값과 비교하여 \% $\mathrm{RVC}$ 값을 산출하였다. 근활성 도의 자료는 3 회 측정하여 얻은 결과의 평균값을 이용하였다. ${ }^{20}$

\section{3) 폐기능 측정}

폐기능은 들숨압력을 측정하였다. 구강 내 압력만을 측정하기 위하 여 코마개를 착용하여 코를 막은 후 Powerbreathe K5 (Powerbreathe, $\mathrm{UK}$ 장비의 프로그램 내 측정항목을 사용하여 실시하였다. 앉은 자 세에서 공기가 새지 않도록 최대한 입술에 측정 장비의 마우스피스 를 밀착시켜 물고 정면을 바라보고 앉아 시작 신호를 기다리게 하였 다. 대상자는 잔기량(Residual Volume)에 최대한 가깝게 날숨을 한 후 치료사가 '시작' 신호를 보내면 대상자는 즉시 최대한 깊고 빠르게 1 초 이상 들숨을 지속하도록 하였다. 가장 강한 들숨을 시도하여 한 번 실시할 때, 1 초 이상 곡선이 유지되도록 실시하였으며, 총 10 회를 실시하여 평균값을 사용하였다. 측정은 운동 전후 각각 2 회 측정하 였다(Figure 2).

\section{4. 자료분석}

측정된 자료는 SPSS 18.0 을 이용하여 통계처리 하였으며, 대상자의 동 질성 검증을 위해 독립표본 t-검정(independent t-test)을 실시하였다. 중재방법에 따른 그룹 간 들숨근 활성도와 폐기능을 비교하기 위해 공분산분석(analysis of covariance, ANCOVA)을 실시하였다. 통계학 적 유의수준은 $\alpha=0.05$ 로 하였다.

\section{결 과}

\section{1. 그룹 간 호흡근 활성도 비교}

1) 위등세모근 활성도 비교 생체되먹임 들숨근 훈련그룹(BIE group)과 가로막 호흡법 훈련 그룹 (DBE group) 간의 위등세모근 활성도를 중재 전후 비교한 결과, $\mathrm{BIE}$

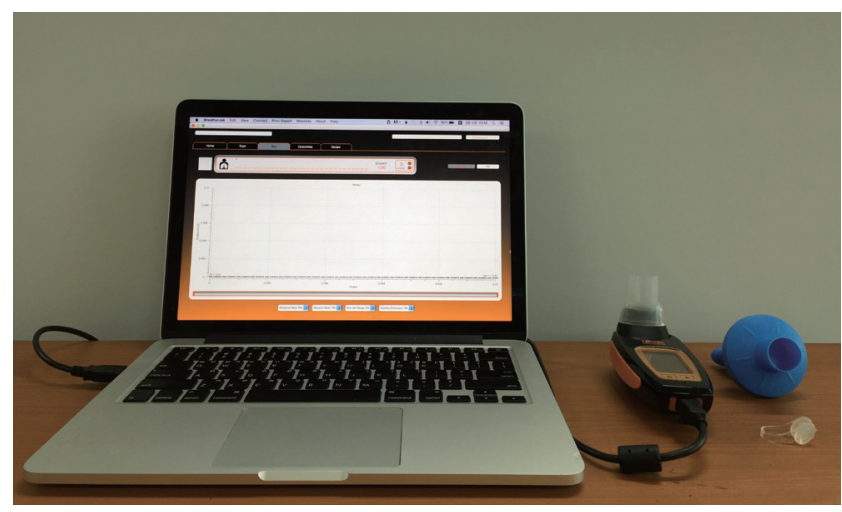

Figure 2. Powerbreathe K5. 
Table 2. Comparison of inspiratory muscle activation between groups

(Unit: \%)

\begin{tabular}{|c|c|c|c|c|c|c|}
\hline & $\mathrm{BIE}$ & $\begin{array}{l}\text { =15) } \\
\text { (1) }\end{array}$ & DBE & $=15)$ & $\mathrm{F}$ & $\mathrm{p}$ \\
\hline & Pre & Post & Pre & Post & & \\
\hline UT & $104.19 \pm 1.84$ & $143.23 \pm 3.89$ & $103.68 \pm 2.16$ & $122.63 \pm 4.62$ & 21.732 & $<0.001^{*}$ \\
\hline LD & $104.51 \pm 2.17$ & $134.78 \pm 4.18$ & $104.20 \pm 2.44$ & $117.23 \pm 3.10$ & 26.389 & $<0.001^{*}$ \\
\hline
\end{tabular}

\%RVC: \% reference voluntary contraction, UT: Upper trapezius muscle, LD: Latissimus dorsi muscle, Mean \pm SD: Mean \pm standard deviation, BIE group: Biofeedback inspiratory muscle exercise group, DBE group: Diaphragm breathing exercise group.

${ }^{*} p<0.001$.

Table 3. Comparison of maximal inspiratory pressure between groups

(Unit: $\left.\mathrm{CmH}_{2} \mathrm{O}\right)$

\begin{tabular}{|c|c|c|c|c|c|c|}
\hline & & & DBE & 15) & $F$ & $p$ \\
\hline & Pre & Post & Pre & Post & & \\
\hline MIP & $34.85 \pm 3.37$ & $43.66 \pm 2.73$ & $35.01 \pm 2.83$ & $37.22 \pm 2.71$ & 24.359 & $<0.001^{*}$ \\
\hline
\end{tabular}

MIP: Maximal inspiratory pressure, Mean \pm SD: Mean \pm standard deviation, BIE group: Biofeedback inspiratory muscle exercise group, DBE group: Diaphragm breathing exercise group.

${ }^{*} p<0.001$

group이 DBE group보다 더 유의하게 활성이 되었다 $(\mathrm{p}<0.01)$ (Table 2).

\section{2) 넓은등근 활성도 비교}

생체되먹임 들숨근 훈련 그룹(BIE group)과 가로막 호흡법 훈련 그룹 (DBE group) 간의 넓은등근 활성도를 중재 전후 비교한 결과, $\mathrm{BIE}$ group이 DBE group보다 더 유의하게 활성이 되었다 $(\mathrm{p}<0.01)$ (Table 2).

\section{2. 그룹 간 최대들숨압력 비교}

생체되먹임 들숨근 훈련 그룹(BIE group)과 가로막 호흡법 훈련 그룹 (DBE group) 간의 최대 들숨 압력을 중재 전후 비교한 결과, BIE group 이 DBE group보다 더 압력이 높았다 $(\mathrm{p}<0.01)$ (Table 3).

\section{고 찰}

뇌졸중 환자는 뇌 손상 부위, 급성기 관리, 회복기간의 자세, 이차적 인 합병증 등으로 심폐 기능에 장애가 오게 된다. 뇌졸중을 비롯한 신경 및 근육질환 환자에 있어 호흡운동은 호흡근의 강화, 지구력, 협 조성의 향상과 가슴 및 등뼈의 가동성을 유지 및 증진시켜 호흡의 효 율성을 높이고 호흡에너지를 감소시키는 데 목적이 있다고 하였다. ${ }^{21}$

본 연구에서는 뇌졸중 환자를 대상으로 시각적 되먹임을 이용한 생체되먹임 들숨근 훈련(BIE)과 가로막 호흡법 훈련(DBE)을 중재하 여 위등세모근과 넓은등근의 활성도, 최대들숨압력의 변화를 비교 하였다. 연구결과 BIE group이 DBE group보다 위등세모근과 넓은등 근이 더 유의하게 활성이 되었으며, 최대들숨압력에서도 BIE group이 $\mathrm{DBE}$ group보다 더 압력이 높게 나타났다.

Lee 등 15 은 중년층 남성 27명을 대상으로 생체되먹임 호흡 훈련 그 룹과 트레드밀을 이용한 유산소 운동 그룹으로 나누어 8 주 동안 주 3
회 50 분씩 중재한 결과 생체되먹임 호흡 훈련을 실시한 그룹에서 흥 곽용적과 폐기능에서 유산소 운동 그룹보다 유의한 차이를 나타내 었다. 본 연구에서는 뇌졸중 환자를 대상으로 하였지만 생체되먹임 들숨근 훈련 그룹에서 가로막 호흡법 훈련 그룹보다 유의한 차이를 보여 선행연구와 동일한 결과를 나타냈다.

$\mathrm{Lee}^{22}$ 는 45 명의 뇌졸중 환자를 대상으로 하여 목 안정화 운동 그룹 과 호흡 재교육 그룹으로 나누어 6주 동안 중재한 결과 두 그룹 모두 에서 몸통근 활성도의 유의한 증가가 나타났으며, 목 안정화 운동 그 룹에서 더 큰 증가를 보였고, $\mathrm{SeO}^{4}$ 는 45 명의 뇌졸중 환자를 대상으로 하여 복합 호흡 훈련과 생체되먹임 호흡 훈련, 호흡법 재교육을 8주 동안 중재한 결과 폐기능 검사 측정에서 1 초간 노력성 날숨량의 노력 성 폐활량에 대한 비, 평상시 1회 호흡량에서 복합 호흡 훈련 그룹이 다른 두 그룹보다 더 유의하게 증진을 나타냈고, 몸통 호흡근의 활성 도에서는 마비측의 위등세모근과 배곧은근에서 호흡 훈련군이 대조 군보다 더 유의하게 증가한 결과를 나타냈다. 본 연구에서는 생체되 먹임 들숨근 훈련과 가로막 호흡법 훈련이 위등세모근과 넓은등근 의 활성도에 유의한 증가를 나타내어 선행연구와 부분 일치하였다.

Britto 등'은 뇌졸중 환자 21 명을 대상으로 가정 운동 프로그램을 이용한 들숨근 훈련을 적용하여 최대들숨압력의 $90 \%$ 의 저항을 제 공하는 그룹과 저항을 제공하지 않는 그룹으로 나누어 8 주 동안 주 5 회 30 분씩 중재한 결과 저항을 제공한 그룹이 최대들숨압력과 들숨 근 지구력에서 유의한 차이를 보였다. 또한 Sutbeyaz 등른 뇌졸중 환 자 45 명을 대상으로 들숨근 훈련 그룹과 호흡법 재교육 그룹으로 나 누어 6주 동안 주 6회 30분씩 중재한 결과 들숨근 훈련 그룹의 최대 들숨압력에서 유의한 차이를 보였다. 본 연구에서도 생체되먹임 호 흡 훈련 그룹이 호흡법 재교육 그룹과 비교하여 최대들숨압력에 유 의한 차이를 보였다. 선행연구와 비교하여 저항의 정도와 중재방법 
간에 차이는 있지만 최대들숨압력을 향상시키는 동일한 결과는 들 숨근 훈련이 뇌졸중 환자의 들숨 능력 향상을 위해 필요하다는 것을 뒷받침해줄 수 있다. 또한 이는 호흡 훈련의 기간은 4-12주, 빈도는 주 $2-5$ 회, 훈련시간은 20-30분을 실시해야 효과가 있다는 연구를 뒷받침 한다. ${ }^{23}$

본 연구에서는 시각적 되먹임을 이용한 생체되먹임 들숨근 훈련 그룹(BIE group)이 가로막 호흡법 훈련 그룹(DBE group)과 비교하여 중재 전후 들숨근 활성도와 폐기능에 유의한 증가를 보여 선행연구 와 부분 일치하였다. BIE group이 DBE group과 비교하여 위등세모근 과 넓은등근의 활성도가 상승한 것은 시간의 흐름에 따라 팔다리 근 력의 호전과 함께 호흡을 담당하는 근육들의 근력 호전이 함께 이루 어졌기 때문으로 생각된다. 또한 최대들숨압력이 더 높게 나타난 것 은 들숨근 훈련을 수행하는 과정에서 시각적 되먹임을 통해 일정한 시간과 강도로 호흡근의 강화시키는 노력성 호흡 훈련을 일으켜 직 접적인 저항성 호흡을 유발해 최대들숨압력의 상승이 생체되먹임이 제공되지 않은 그룹에 비해 더 높은 향상을 보인 것으로 생각된다.

본 연구의 제한점은 특정 지역에서 대상자를 선발하였고, 대상자 의 수가 적기 때문에 일반화하기 어려움이 있으며, 향후 본 연구를 바 탕으로 뇌졸중 환자에게 생체되먹임을 이용한 호흡 훈련을 호흡법 재교육과 함께 병행함으로써 더 효율적인 호흡 물리치료가 될 것으 로 생각되며, 향후 임상적 활용도를 높일 수 있도록 효과에 대한 지속 적인 연구가 필요할 것으로 사료된다.

\section{ACKNOWLEDGEMENTS}

The Research has been conducted by the Research Grant of Sehan University in 2015 .

\section{REFERENCES}

1. Kolb B, Gibb R. Brain plasticity and recovery from earlycortical injury. Dev Psychobiol. 2007;49(2):107-18.

2. de Almeida ICL, Clementino ACCR, Rocha EHT et al. Effects of hemiplegy on pulmonary function and diaphragmatic dome displacement. Respir Physiol Neurobiol. 2011;178(2):196-201.

3. Macko RF, Ivey FM, ForresterLW et al. Treadmill exercise rehabilitation improves ambulatory function and cardiovascular fitness in patients with chronic stroke. Stroke. 2005;36(10):2206-11.

4. Seo KC. The effect of pulmonary function and respiratory muscle activity in the stroke patients after complex breathing exercise. Daegu University. Dissertation of Doctorate Degree. 2012.

5. Yun JH, Kim TS, Lee BK. The effects of combined complex exercise with abdominal drawing-in maneuver on expiratory abdominal muscles ac- tivation and forced pulmonary function for post stroke patients. J KoreanSocPhys Med. 2013;8(4):513-23.

6. Lee JH. The effect of pulmonary function in the stroke patients after feedback breathing exercise. Daegu University. Dissertation of Master's Degree. 2008.

7. Lanini B, Bianchi R, Romagnoli I et al. Chest wall kinematics in patients with hemiplegia. Am J Respir Crit Care Med. 2003;168(1):109-13.

8. Kim MH, Lee WH, Yun MJ. Effects on respiratory strength training on respiratory functionand trunk control in patient with stroke. J Kor Phys Ther. 2012;24(5):340-7.

9. Stubeyaz ST, Koseoglu F, Inan L et al. Respiratory muscle training improves cardiopulmonary function and exercise tolerance in subjects with subacute strok: A randomized controlled trial. Clin Rehabil. 2010; 24(3):240-50.

10. Lee JH, Kwon YJ, Kim k. The effect of chest expansion and pulmonary function of stroke patients after breathing exercise. The Journal of Korean society of physical therapy. 2009;21(3):25-32.

11. Kim CB, Choi JD. Effects of chest expansion resistance exercise on chest expansion and maximal inspiratory pressure in patients with stroke. J Korean Soc Phys Med. 2015;10(1):15-21.

12. BrittoRR, Rezende NR, Marinho KC et al. Inspiratory muscular training in chronic stroke survivors: A randomized controlled trial. Arch Phys Med Rehabil. 2011;92(2):184-90.

13. Seo KC, Jo MS. The effects of feedback respiratory exercise on gait ability in patients with stroke. J Korean Soc Phys Med. 2013;8(4):559-66.

14. Lee JY, Jung JH, Chung EJ et al. The effect of feedback breathing exercise and treadmill exercise on chest length and pulmonary function of the middle-aged. Journal of Special Education \& Rehabilitation Science. 2013;52(3):319-33.

15. Park SK, Kang JY. Effects of EMG-Biofeedback training on functional ability and Q-angle in patellofemoral pain syndrome. J Kor Phys Ther. 2014:26(2):68-73.

16. Klusiewicz A, Borkowski L, Boros P et al. The inspiratory muscle training in elite rowers. J Sports Med and Phys Fitness. 2008;48(3):279-84.

17. Pradon D, Roche N, Enette L et al. Relationship between lower limb muscle strength and 6-minute walk test performance in stroke patients. J Rehabil Med. 2013;45(1):105-8.

18. Jones AY, Dean E, Chow CC. Comparison of the oxygen cost of breathing exercise and apontaneous breathing in patients with stabel COPD. Phys Ther. 2003;83(5):424-31.

19. Kim JH. The effects of whole body vibration exercise on jump performance and quadriceps muscle activation in soccer player. J Kor Phys Ther. 2015:27(3):129-34.

20. Kim JH. The effects of whole body vibration exercise on balance and lower extremity muscle activity in stroke patients. J Kor Soc Phys Ther. 2013;25(5):266-72.

21. Shin JB. Post-stroke complication. KJFM. 2002;23(1):13-22.

22. Lee MH. Effects of the neck stabilizing exercise combined with the respiratory reeducation exercise on breathing function in patients with stroke. Daegu University. Dissertation of Doctorate Degree. 2013.

23. British Thoracic Society Standards of Care Subcommittee on Pulmonary Rehabilitation. Pulmonary rehabilitation. Thorax. 2001;56(11): 827-34. 